\title{
Negotiations, Initiatives, and Arms Reductions
}

J. David Singer*

University of Michigan, Ann Arbor, Michigan, USA

\section{Glimmers of hope}

Despite the sorry state of East-West relationships, with policies of detente in a shambles, and the virtual cessation of Soviet-American negotiations on arms reduction and other matters, there remain two faint glimmers of hope that reason and responsibility have not totally disappeared from contemporary world politics. One of these is the recent increase in concern among the major powers' allies on both sides, and a consequent tendency toward greater initiatives emanating from European capitals. It may even be that it takes a sequence of events as ominous as the Euro-missile crisis to remind the European elites that they need not be merely accomplices - and victims - of Soviet and American stupidity, but that they have both the responsibility and the possibility of bringing Moscow and Washington to their senses.

The second is that the super-powers - even as they continue to over-arm, to threaten, and to demonstrate 'resolve' - appear to be inching toward a new approach to the arms race dilemma. The more traditional approach, going back to the $1920 \mathrm{~s}$, has been upon the slow negotiation of infrequent, but fairly comprehensive treaties, intended to set upper limits for the signatories in one or a few weapon categories. Seldom have actual reductions been sought, but even the establishment of agreed ceilings has been of only a temporary sort, soon to be eroded by inadvertent or conscious violations, or by advances and shifts in

*J. David Singer is Professor of Political Science, University of Michigan weapons technology. And despite the salutary results of the ABM and SALT I negotiations, the vertical and horizontal proliferation of strategic (and even 'conventional') weapons has continued apace since World War II. More weapons of an increasingly provocative and destabilizing nature are in the hands of more nations than ever before, and never have the objective and subjective conditions for tuming away from major power war been less promising.

Might there be a more effective approach to arms limitation and arms reduction? Must we continue, like Sisyphus, to struggle manfully up the slippery slope, hoping that each heroic effort will finally bring us success, only to discover that we are further than ever from the plateau of arms stabilization? Before suggesting an altemative, let me indicate why the search for periodic, large, dramatic, one-shot agreements has proven so inadequate.

\section{Why high-stakes negotiation often fails}

Without getting into the 'origins of the cold war' swamp, let us recognize that nearly forty years of intense East-West rivalry not only produces distrust and hostility between the protagonists, along with an inexorable growth in the arsenals of war, but also some menacing changes within the contending societies as well. At each choice point, certain selfamplifying processes are strengthened. That is, when we choose to develop or deploy a new weapon system, we strengthen the position of those who supported it and weaken the position 
of those who opposed it. Each allocation of resources to the military adds to the economic clout of those who advocated it, and detracts from those who resisted it. And each decision to 'hang tough' enhances the domestic credibility of the hard-liners and diminishes that of the more prudent and moderate elements. Further, with each such choice, the cumulative influence of the 'hawks' increases, while that of the 'owls' and the 'doves' decreases.

Periodically, of course, a marginal consensus emerges that confrontational policies and arms build-ups may not be working, and this awareness typically leads to experimentation with less bellicose behavior. But given the increasingly dominant position of the hard-line factions in the rival power, as well as the endemic suspiciousness that has inevitably developed, such 'experiments' are not likely to work. When concessions are offered, they are not promptly reciprocated, and when positive initiatives are attempted, they are often rebuffed. And by the time that the rival government finally chooses to respond in kind, it is too late. Once again, the hawks have demonstrated that 'there is only one way to deal with those people', and the voices of reason are soon silenced or ignored.

Admittedly, we sometimes see a groundswell of opinion in favor of less belligerent policies, but it rarely endures. Whether it be motivated by a recognition of the dangers to national security, an awareness of the economic consequences of a continuing arms race, mere weariness, or even a resurgence of pacifism, two factors usually stem that tide with relative ease. One is the tendency of the rival to be quite unhelpful - even to the point of increasing its provocative behavior - thus discrediting the nascent 'peace movement'. The other is the domestic counter-attack mounted by those who, for material, psychological, or institutional reasons prefer the continuation or resumption of more militaristic policies.

In addition to these vested interests - as well as those who are naive enough to believe in the arms race as an acceptable basis for national security - there is another obstacle to success. I refer here to the psychological syndrome that inevitably goes with negotiations over very high stakes. First, there is the anxiety that we might 'give something away' that could tum out to be vitally damaging to the nation's security. Hence, we are likely to agonize over every detail of substance or procedure, looking for some hidden danger, and call in all sorts of specialists and technicians to double check. This not only takes a lot of time, but it creates great opportunities for different agencies and offices to obstruct or scuttle a given move. Second. considering the breadth and magnitude of the possible bans and limitations, excessive and time-consuming attention will be given to the possibility of second- and third-order implications for future strategic developments. Third, with so much at stake, the natural suspicion of the other side's motives and honesty is further exaggerated, providing a field-day for the devotees of 'worst case analysis".

Fourth, the longer and more acrimonious the discussions within and between tha delegations, the greater the opportunity for frustration, suspicion, and hostility to fester. Fifth, the combination of technical, strategic, and emotional complexities tends to make the chief negotiators even more cautious than they normally might be. Finally, given the significance of the putative agreement and the cumulative clout of the domestic opposition to meaningful arms control, the negotiators will constantly be looking over their shoulders to be sure that they are not politically vulnerable back home to charges of being 'soft'. Given these dynamics, it is not surprising that so many can labor so long, and accomplish so little.

\section{Why low-stakes negotiation might succeed}

If this diagnosis is essentially correct, we need a strategy that recognizes the powerful forces political, economic, and psychological - which stand in the way of major breakthroughs in arms negotiations or other security-related efforts. The domestic resistance and technical difficulties must be overcome in a more pragmatic and piece-meal fashion, and the oppo- 
nents' skepticism must be ameliorated in an equally gradual manner. All of this points, then, to the more incremental and fluid strategy in pursuit of arms control and arms reduction that seems to be developing.

If we look at the ways in which nations handle the equally complex incompatibilities of interest while nevertheless pursuing certain shared objectives in other realms, we may find an instructive example. In trade, investment. immigration, technology transfer, and even in many areas of diplomacy, we ordinarily find a pattern quite different than that employed in the high politics security sector. The negotiation process is more continuous, the agreements pursued are more limited, the results are more short-range, and the ebb-flow more fluctuating.

This emphasis on fluid, incremental, and low stakes bargaining offers certain advantages that might be applicable to arms negotiation. By working in the context of a continuous process, there is greater opportunity for shortrun feedback in which small errors can be rectified, minor misperceptions modified, temporary violations alleviated, and momentary stalemates side-stepped. Further, the incremental process permits rolling readjustments and frequent multiple trade-offs within the domestic bargaining context. As modest gains are registered, the resistance of some agencies and interest groups might be softened, and the credibility of others enhanced. And as the costs and dangers of current policies are haltingly and erratically reduced, one might expect modest shifts in the distribution of domestic opinion as well as in the distribution of influence.

\section{Some useful pre-conditions}

For such a process to really take hold, and for the resistance of the hawks and the confidence of the doves to reverse direction, three additional activities would be highly desirable. One is to address and try to ameliorate the material and symbolic costs that would be incurred by those in each society who have stood to gain by the arms race and the accompanying hardline policies. Not only economic conversion and job-retraining, but a range of other adaptive moves would be necessary to bring more groups into the pro-arms control coalition. And as these elements - in both the Western and Soviet camps - gain confidence and credibility while the forces of resistance begin to compromise, come around, or drop out, the ability to withstand temporary reverses would be enhanced.

A second set of efforts would be in the direction of economic, cultural, and diplomatic reinforcement of these incremental processes. As minor limitations and reductions of arms levels begin to emerge. East-West collaboration in these other sectors might become more feasible, and thus strengthen the overall tendencies toward detente. Some would contend that such confidence-building measures must precede any progress in arms control, but this seems much more necessary if we continue to strive for dramatic big breakthroughs than if we shift to the more incremental, processoriented mode. Under the latter strategy, it would be less critical which sectors we concentrate upon first; continuous exploration, probing, and horsetrading could proceed whenever the incentives are strong enough and the obstacles - domestic and foreign - sufficiently surmountable.

A third critical emphasis would be that of an increasing role for the United Nations system. particularly the Secretariat. I see this as threepronged. One is the need for a gradual shift away from sole reliance upon national means of verification and monitoring of the various limitations and restrictions that have been negotiated. Another would see the UN playing a more active role in the mediation of the disputes that must inevitably arise in such a complex, delicate and dangerous process as moving to some sort of durable arms control regime. The third prong here is that of an increasingly active role for the Office of the Secretary-General in preventive diplomacy and the institution of confidence-building measures. While the so-called 'conference diplomacy' of the Assembly and the Council continues, with little effect, it is desirable that the Secretariat staff initiate a process of what 
might be called 'coalition diplomacy'. In this vein, past emphasis on the passive availability of the Secretary-General (when requested by governments) would shift to a more active and vigorous intervention into nascent or ongoing disputes and difficulties. If handled in a skillful, tactful, and competent fashion, such a new set of initiatives might be found less obtrusive and more welcome than has been traditionally assumed.

\section{A few possible initiatives}

If, as suggested, we may expect greater activity on the part of the super-powers' allies (and perhaps even on the part of the nonaligned governments) and some shift toward more modest, pragmatic, and flexible negotiating strategies on the part of the Americans and the Soviets, what might be done to get things moving? Are there some plausible initiatives that might help to improve the climate and thus increase the attractiveness - and the likelihood of success - of such low-stakes negotiations? Given my conviction that the only really effective confidence-building measure is arms reduction itself, where might we look to attempt a new beginning? In as much land-based counter-force missiles, both in Europe and America, are the major source of anxiety and the dominant source of no-confidence in the intentions of the rivals, these highly provocative and de-stabilizing weapons ought to get our highest priority. Would it be too much to expect one or both of the superpowers to recognize this fact. grasp that these weapon systems are a serious threat to their own security as well as their rival's, and put a halt to further deployment and 'modernization' of land-based nuclear delivery vehicles? Would it be too much to expect the political leadership in these over-militarized societies to act responsibly on behalf of their own citizens as well as the rest of the human race?

It probably is asking too much, given the extent to which the US and the USSR have been morally and intellectually corrupted by their arms rivalry, but if there are any elements left in these countries who have both the power and the intelligence. they will move heaven and earth to halt, and then reverse, the deployment of vulnerable and accurate ballistic missiles anywhere. Having decided, and acted for national and global survival by putting a stop to further deployment - with or without reciprocity - their next step would be to begin an incremental phasing out of existing landbased systems. I do not argue here that seabased or air-launched nuclear systems are the benefactors of humanity, but their existence is a less immediate threat to the human race, and can be dealt with when - and if - we see some signs of progress in reducing the number of essentially first-strike systems.

\section{Conclusion}

There are of course, several other ways of breaking into the arms-tension spiral, and we ought to be willing to accept and encourage any reasonable initiative from either side that holds any promise for a reversal of this deadly process. But it seems absolutely essential that we forget about the 'go-for-broke' negotiations and start a process of unilateral initiatives, piece meal offers, tacit concessions, and flexible coordination between the major powers and their allies, while attending carefully to the domestic processes by which we might break the stranglehold of those who have edged us closer and closer to the nuclear abyss. 